\title{
Hypnic jerks possibly induced by escitalopram
}

\author{
Harshal Sathe, Sagar Karia, Avinash Desousa, Nilesh Shah
}

Department of Psychiatry, Lokmanya Tilak Municipal Medical College, Mumbai, Maharashtra, India

\section{ABSTRACT}

Hypnic jerks or sleep starts are benign myoclonic jerks that usually occur on falling asleep. Various factors like excessive caffeine intake, physical, and emotional stress can increase their frequency. Here we report a case of a female who suffered from hypnic jerks with use of selective serotonin reuptake inhibitor drug escitalopram and responding to treatment with clonazepam.

Key words: Escitalopram, hypnic jerks, selective serotonin reuptake inhibitor

\section{Introduction}

Hypnic jerks or sleep starts are benign myoclonic jerks that everyone experiences sometimes in a lifetime. Although they resemble the jerks of myoclonic seizures, they occur on falling asleep and are just benign nonepileptic phenomena. They occur at all ages and the patient complaining of hypnic jerks is often given a thorough epileptic evaluation. ${ }^{[1]}$ They are easily identified on video electroencephalography (EEG) or normal EEG monitoring by the fact that they occur in wake to stage 1 sleep and have no epileptic correlates on EEG, but rather show a muscle artefact pattern. Furthermore, known as predormital myoclonus, hypnic jerks usually consist of a single contraction that often affects the body asymmetrically. ${ }^{[2]}$ The jerk may be either spontaneous or induced by stimuli. Sleep starts are sometimes associated with the subjective impression of falling, a visual sleep start (sensation of blinding light coming from inside the eyes or head), an auditory sleep start (loud snapping noise that seems to come from inside the head) or a visual hypnagogic dream or hallucination. ${ }^{[3]}$ Pure sensory phenomena in the absence of a body jerk (so-called "sensory sleep starts") can also occur. Excessive caffeine

\begin{tabular}{|l|l|}
\hline \multicolumn{2}{|c|}{ Access this article online } \\
\hline Quick Response Code: & Website: \\
\hline & www.ruralneuropractice.com \\
\hline & \\
\hline
\end{tabular}

or other stimulant intake, prior intense physical work or exercise, and emotional stress can increase the frequency and severity of sleep starts. ${ }^{[3,4]}$ Here we report a case of a female, who suffered from hypnic jerks with use of selective serotonin reuptake inhibitor drug Escitalopram and responding to treatment with Clonazepam.

\section{Case Report}

A 45-year-old housewife had come to our outpatient department with complaints of persistent sadness of mood and decreased interest in daily activities since 2 months. She would not find pleasure in activities like watching television or talking to neighbors, which she used to like previously. She also would occasionally have crying spells without any reasons. She would feel that her life is a waste and that it was better to die rather than live such a life. However, there was no history of any suicidal attempt or any self-harm behavior. Her sleep and appetite had also decreased. She also started remaining withdrawn, not talking much, and not taking part in household activities. These complaints had started 2 months back when she got separated with her husband due to an altercation with him. She claimed that there used to be constant verbal altercations between them since the past 20 years of their marital life over varied issues. But this time, the fight led her to leave his house and stay with her mother, though they had not filed for a divorce. There was no previous history of similar complaints. She did not have any manic features, delusions, hallucinations or obsessive-compulsive symptoms. Her past medical and surgical history was

Address for correspondence:

Dr. Avinash Desousa, Carmel, 18, St. Francis Road, Off S.V. Road, Santacruz West, Mumbai - 400 054, Maharashtra, India.

E-mail: avinashdes888@gmail.com 
also insignificant. There was no history of psychiatric illness in her family. On mental status examination, she was groomed normally and demonstrated occasional crying for a few minutes during the interview. Her mood was sad and she conveyed ideas of hopelessness, helplessness, and worthlessness. We diagnosed her as having Major Depressive Disorder as per Diagnostic and Statistical Manual 5 criteria and started her on escitalopram $10 \mathrm{mg} /$ day in divided doses. On regular follow-up, in 2 weeks she showed $40 \%$ improvement in her symptoms, so we continued the same. 6 weeks after being on escitalopram therapy, she reported that she noticed jerky movements of her leg that occurred just as she was beginning to fall asleep often causing her to awaken suddenly for a moment. The jerky movement would characteristically occur in 15-30 min after falling asleep. Initially they would occur once a night, but later the frequency increased to twice or thrice every night. She also started having difficulty in falling asleep and would not get proper sleep. She thus developed daytime fatigability and sleepiness. There was no history of accompanying unconsciousness or any frothing at the mouth or uprolling of the eyeballs or any abnormal involuntary movements during daytime. She denied any history of nightmares or night terrors or other parasomnias. She was diagnosed as having sleep starts or hypnic jerks. She was reassured and was started on clonazepam $0.5 \mathrm{mg}$ at night. After 10 days of starting Clonazepam, she reported a significant reduction in her jerky limb movements. We have tried to reduce clonazepam and take patient off clonazepam but the patient was very much apprehensive of recurrence of jerks so requested us to let her be on same, so she is still on clonazepam and well maintained.

\section{Discussion}

Various hypotheses have been proposed in the etiology of hypnic jerks. One of them states that these jerks are a natural step in the transition from alertness to sleep made via the reticular activating system, where some of the nerves of the hands and legs misfire. Yet another theory states that it is a basic protective reflex. Complete relaxation of the muscles is interpreted by the brain as falling and in order to prevent this the brain orders the muscle to twitch. ${ }^{[5]}$ Polysomnography can be helpful in confirming the diagnosis which can also be done clinically. ${ }^{[5]}$ Differential diagnosis of hypnic jerks includes myoclonic seizures, rapid eye movement behavior sleep disorder, rhythmic movement disorder, benign sleep myoclonus of infancy, etc. From a prognostic perspective, these are benign phenomena, but they need to be treated if they interfere with one's sleep. The management includes nonpharmacological methods such as reducing caffeine intake, exercise in moderation during the daytime, and improved sleep hygiene with most importantly psychological reassurance to the patient. If needed, rapid onset benzodiazepines are the drugs of choice. ${ }^{[6]}$ On a thorough literature search, we did not find any case report on escitalopram induced hypnic jerks and this is a rare, but unique side effect that clinical psychiatrists need to be cognizant of.

\section{References}

1. Derry CP, Duncan JS, Berkovic SF. Paroxysmal motor disorders of sleep: The clinical spectrum and differentiation from epilepsy. Epilepsia 2006;47:1775-91.

2. Fryer J. Hypnic reflex: A spinal perspective. J Sleep Disord Ther 2014;3:5-6.

3. Frenette E, Guilleminault C. Nonepileptic paroxysmal sleep disorders. Handb Clin Neurol 2013;112:857-60.

4. Lozsadi D. Myoclonus: A pragmatic approach. Pract Neurol 2012;12:215-24.

5. Vetrugno R, Montagna P. Sleep-to-wake transition movement disorders. Sleep Med 2011;12 Suppl 2:S11-6.

6. Avidan AY. Parasomnias and movement disorders of sleep. Semin Neurol 2009;29:372-92.

How to cite this article: Sathe $H$, Karia S, Desousa $A$, Shah $N$. Hypnic jerks possibly induced by escitalopram. J Neurosci Rural Pract 2015;6:423-4.

Source of Support: Nil. Conflict of Interest: None declared. 